\title{
Opportunities and Challenges of Inverted Classroom to the Young Teachers in Universities
}

\author{
He Chunfeng ${ }^{1, *}$, Wang Dongliang ${ }^{2}$, Gao Jinhe ${ }^{1}$ and Wang Qiaohuan ${ }^{2}$ \\ ${ }^{1}$ School of Civil \& Architecture Engineering, East China University of Technology, Nanchang, \\ Jiangxi, 330013, China
}

${ }^{2}$ School of Water Resources and Environmental Engineering, East China University of Technology,

Nanchang, Jiangxi, 330013, China
${ }^{* 53262205 @ q q . c o m}$

\begin{abstract}
Inverted classroom as a new teaching model which advocates learning knowledge outside class and internalization knowledge in class totally inverts the traditional teaching mode. It emphasizes center status of students and utilizes modern information technology to realize its teaching goal. So it has been received wide attention from the educational researchers and caused a wave of reform in education teaching. Based on introducing the concept and characteristics of inverted classroom, this paper analyzes the present situation of young teachers who takes major teaching responsibility in universities, and then expounds the opportunities and challenges brought by inverted classroom for young teachers. For opportunities, it contains opportunity of self-improvement, opportunity of building the good relationship with students, etc. For challenges, it contains the challenge of career value, the challenge of teaching ability, etc. In order to make sure the inverted classroom can be effectively implement and hope to provide some reference for every young teacher, it is necessary for young teachers to understand opportunities and challenges, and try their best to seize the opportunities, and improve themselves to conquer the challenges.
\end{abstract}

Keywords: young teachers; inverted classroom; opportunities and challenges

\section{Introduction}

At present, the information technology has greatly impact on the education. With the development of information technology, the traditional teaching methods, imparting knowledge methods are changed. So the reform of education is inevitable. More and more internet teaching methods are used in education to improve teaching model, such as MOOCs, Inverted Classroom, Mini courses, and so on. These courses trigger a tide of education reform, especially inverted classroom which advocates the teaching education concept of "student-centered" is a training environment to use both simple education activities and lectures ${ }^{[1,2]}$. For inverted classroom, it inverts the in-class and out-of-class activities of traditional teaching ${ }^{[3]}$, not only brings unprecedented attention of scholars from domestic and overseas, but also brings the opportunities and presents huge challenges for teachers especially young teachers in universities. Nowadays, for young teachers, they have become the main force in universities, therefore, to great extent, their teaching ability determines teaching quality and level ${ }^{[4]}$. In view of this, this paper introduces the concept and characteristics of inverted classroom, and analyzes present situation of young teachers, and then elaborates the opportunities and challenges which are brought by inverted classroom for young teachers. So in order to make sure the inverted classroom can be effectively implemented and want to provide some reference for young teachers, it is high time for young teachers to understand their own leading roles in teaching and face the challenges positively.

\section{The Inverted Classroom}

\subsection{The Concept of Inverted Classroom}

Inverted classroom also known as "flipped classroom" or "reverse class" inverts teaching sequence ${ }^{[5]}$. It is a new teaching model which uses modern network technology to realize teaching process. The inverted classroom comes from two chemistry teachers named Jon Bergmann and 
Aaron Sams in Colorado Rocky Mountain School of USA in 2007. In 2011, inverted classroom appealed attention from educators in the world by Khan Academy which was founded by Salman Khan in 2004. The inverted classroom inverts the in-class and out-of-class activities, often by taking lecture contents out of classroom and conducting face-to-face discussion during class time ${ }^{[3]}$. Its' teaching model contains three stages. The first stage is before class, teachers design the course contents in different form (audio, video, flash, etc.) and upload them to internet; students learn knowledge through internet by themselves. The second stage is in class, teachers organize students to communicate with each other and answer the difficult questions which students can't solve; students can absorb knowledge very well and internalize knowledge. The third stage is after class, teachers tutor students on line and improve their teaching; students summarize knowledge, use knowledge in practice, and finish homework to sublime knowledge. The inverted classroom teaching model is shown in Figure 1.

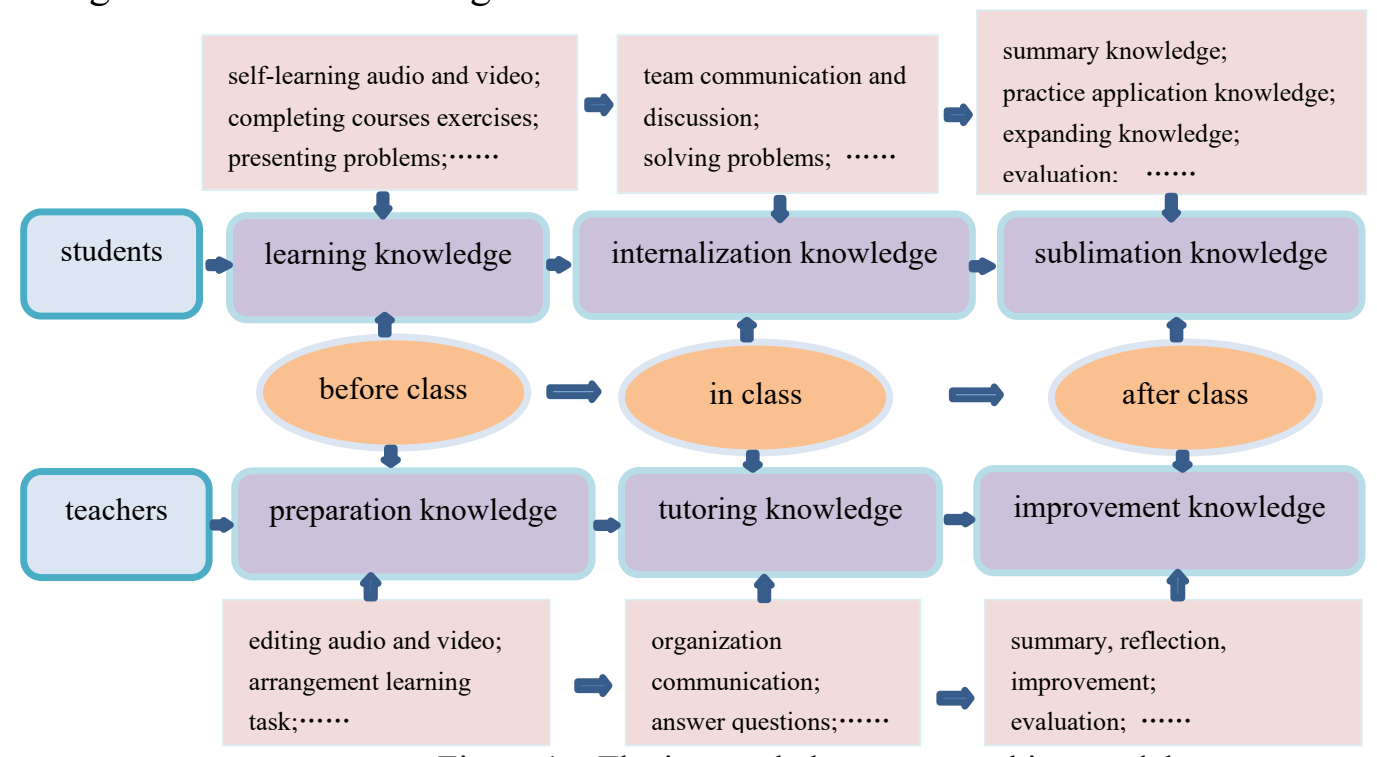

Figure 1 The inverted classroom teaching model

\subsection{The Characteristics of Inverted Classroom}

According to the teaching model of inverted classroom, it is obvious that inverted classroom emphasizes on training self-learning ability and ability of practice conducive to long-term development for students ${ }^{[5]}$. There are several characteristics as follow.

(1) Highlighting the Learning Central Position of Students

Inverted classroom advocates giving the learning stage to students. During the whole learning process, students play a central status to learn knowledge by themselves. They can make their own learning schedule to learn knowledge beforehand. In class, they can communicate and discuss with other students and teachers to solve the questions which they can't solve by themselves, and then they review knowledge and finish homework after class. This learning process changes traditional imparting knowledge by teachers. So the inverted classroom which highlights students' self-learning will help students to realize their individualized learning-aim.

(2) Changing the Role of Teachers

In inverted classroom, teachers' role has been changed from spoon-feeders into new designers, guiders and promoters. They should design suitable learning contents before class. In class, they should organize students to communicate and discuss, and solve common problems and guide personal problems. After class, they should analyze students' learning results and find their unsuitable teaching contents and improve them. So in whole teaching process, teachers should participant and help students to learn, and can communicate with every student. It can make good relationship between teachers and students, students will feel comfortable to talk with teachers about their questions, and they can learn enthusiastically and get motivated.

(3) Diversification the Learning Ways 
Inverted classroom changes the limitation of traditional learning time and place, and students can learn knowledge at any time and any place. They can use various kinds of modern tools (computer, iPad, etc.) to finish their learning and use different communication techniques (online platform, QQ, etc.) to communicate with other students and teachers to help them understand, consolidate knowledge. These ways are just right to use modern network technology to teaching. It can stimulate students' interest and enthusiasm in learning.

\section{Analyses the Present Situation of Young Teachers in Universities}

With popularization of higher education, more and more $\mathrm{PhD}$ graduates and postgraduates enter into universities as young teachers. On the one hand, these young teachers have the characteristic of high academic level, solid professional knowledge, strong ability of science research, high modern technology level, and so on ${ }^{[6]}$. So young teachers can easily use modern tools and technology to edit audio and video files, manage and preserve online files, and communicate with students online, and so on. These can help them to meet the technical requirements of inverted classroom. Young teachers bring a tide of "fresh blood" to traditional teachers-team and promote development of traditional teachers-team.

On the other hand, most of young teachers haven't take in the format teacher-training as they start their teaching career in universities. Therefore, in process of teaching, they have to face too many problems and expose many shortcomings. First, in the aspect of teaching cognitive, many young teachers don't adapt to teacher's role when they stand on the platform. Therefore, they lack correct analysis and judgment in teaching objectives, teaching methods, teaching strategy and situation, and so on. Second, in the aspect of study and application of teaching theoretical knowledge, especially teaching basic skills ${ }^{[7]}$, many young teachers have a big gap between their professional skills and students' requirement, such as the ability of communication with students, blackboard writing ability, language expressive ability, practical guidance ability ${ }^{[7]}$, and so on. Third, in the aspects of professional value orientation, many young teachers pay much more attention to science research than teaching ${ }^{[8]}$. The very important reason is the effect of teacher technical post promoting system which evaluates science research program, science paper, etc. As a result, they don't willing to take energy into teaching and even give up the teaching task. So it is necessary to improve the present situation of young teachers in universities and to make sure that young teachers can better adapt to the development of teaching model in universities.

\section{The Opportunities and Challenges of Inverted Classroom to Young Teachers in Universities}

\subsection{The Opportunities for Young Teachers}

Inverted classroom is a new teaching model and bring a reform in educational world. According to the concept of inverted classroom, it can be known that it gives the good opportunities for young teachers in universities.

(1) Providing the Condition of Self Improvement

Teachers, including young teachers, are not only the creators and executor in the activities of education teaching, but also are the learners in the process of education teaching ${ }^{[9]}$. In inverted classroom, it can provide many online teaching resources that young teachers can easily utilize the existing online teaching resources to learn. In process of online-study, young teachers can master teaching methods and techniques with little time and energy to spend. As a result, they can easily prepare instructional materials, design instructional process, and make instructional audio and video files. Therefore, with the development of inverted classroom, more and more online lessons will be developed; these online lessons will provide more studying resources for young teachers to improve their teaching ability.

(2) Providing the Possibility of Building the Good Relationship with Students

In inverted classroom, communicating between teachers and students plays an important role in the whole teaching process. Teachers and students' relationship will be transferred from traditional 
opposite position to unified position. Therefore, as for teacher's age, compared with old teachers, young teachers have unique advantage, so they can easily be "friends" with students. Communicating with young teachers in teaching process, students feel no constraints or pressure, so they have much more enthusiasm and participation in communicating with them than with old teachers in class. As a result, young teachers can easily understand learning situation of students and can give the specific guidance for each student.

(3) Providing the Chance from Application of Modern Information Technology

Inverted classroom mainly utilizes modern information technology to realize the whole teaching, such as audio and video editing, files creation and management, online platform construction and application, etc. This is the trend of the development of science and technology. Comparing with old teachers, young teachers have more chances to study how to use modern information technology to deal with different kinds of valuable information in practice. So in inverted classroom, the skill of application of modern information technology can help young teachers to be qualified for education career. In order to improve students' learning interest and achieve the anticipate effect before class, young teachers are able to make high quality teaching video lessons for students to learn.

\subsection{The Challenges for Young Teachers}

As we know, opportunities coexist with challenges. Inverted classroom not only brings the opportunities for young teachers, but also presents the enormous challenges for young teachers.

(1) The Challenge of Young Teachers' Career Value

The value can guide people what to do and which to collect and then it can impel people to design their goals and try their best to realize their goals. For young teachers, their education career has just begun, comparing with old teachers, they have more time and energy need to spend on teaching. But in most universities, the results of scientific research can not only reflect young teachers' value, but also can promote their professional title; this compels young teachers to spend a lot of time and energy on scientific research. So under the long-term influence of scientific research value, teaching research has already been ignored and the quality of education in universities becomes worse and worse. Therefore, it is high time for young teachers to realize teacher's primary responsibility. Especially with the coming of inverted classroom which requires young teachers participate in whole teaching process, which is, before class, in class and after class. It is obvious that the traditional scientific research value can't effectively finish the goal of inverted classroom. If universities want to implement inverted classroom, the teaching value of young teachers is very important and essential. So in order to ensure the sustainable development of education, young teachers' career value faces enormous challenge in inverted classroom.

(2) The Challenge of Teaching Ability

Young teachers' ability is not only the key factor for development of universities in future, but also embodies their own comprehensive qualities which contain personal ability, function and status, etc. In inverted classroom, the tasks of young teachers are designing teaching contents, editing audio and video, organizing class discussion, online interactive, etc. Higher teaching ability is more needed than in traditional teaching. But at present, young teachers have low teaching ability in the whole process of teaching which includes teaching design, organizing and imparting knowledge, managing classroom activity, etc. Facing the reform of teaching model, young teachers should try their best to improve their own teaching ability. This can make inverted classroom implemented effectively and efficiently. Therefore, inverted classroom presents huge challenge for young teachers.

(3) The Challenge of Profession Comprehensive Knowledge

In traditional classroom, young teachers just prepare for delivering of the course which should accord with the course syllabus and impart knowledge to students. They think that if they can complete the course teaching and solve the problems of their profession field, these will be enough. As a result, they often ignore the correlation between their own profession knowledge and the others. But in inverted classroom, the process of learning knowledge is before class, the process of internalization knowledge is in class, which requires young teachers not only have the profound 
knowledge of their own profession, but also have knowledge of other professions and disciplines. If they have the rich knowledge of different professions and disciplines, and also have the ability of update knowledge, they would design short and pithy teaching videos and prepare many possible problems in advance, and when they communicate with students in class they would take students' problems in stride. In order to cater for inverted classroom, different kinds of profession comprehensive knowledge are necessary, and it presents great challenge for young teachers.

\section{Conclusions}

As a kind of new teaching model, inverted classroom emerges and develops along with modern information technology and it is affecting the development of higher education with great speed. As the soul engineer of education, teachers, especially young teachers who are the future of universities should not only understand the concept and characteristics of inverted classroom, but also understand the opportunities and challenges which brings by inverted classroom. In short, in order to ensure inverted classroom can really acquire its goal for teaching reform, young teachers should adapt to inverted classroom, and then hold a positive attitude to face development trend. Only by doing so, can young teachers continuously get well development, and can ensure benign development of teaching quality in universities.

\section{Acknowledgement}

This work was financially supported by Reform Research Subject of Higher Education in Jiangxi Province of China, (Grant NO: JXJG-15-6-11, JXJG-16-6-20).

\section{References}

[1] M. J. Lage, G. J. Platt, and M. Treglia, "Inverting the classroom: A gateway to creating an inclusive learning environment," Journal of Economic Education, Vol. 31(1) (2000), p.30-43.

[2] J. H. Dai and J. J. Shen, "The Transformation of Teachers' and Students' Roles in Flipped Classroom," Journal of Nan Jing Xiao Zhuang University, No. (6) (2016), p. 121-124, in Chinese.

[3] M. J. Lage, G. J. Platt and M. Treglia, "Inverting the classroom: A gateway to creating an inclusive learning environment," The Journal of Economic Education, Vol. 31 (2000), p. 30-43.

[4] L. M. Yao, G. M. He and W. Y. Duan, "The Current Status of Young Teachers' Instructional Development in Key Universities and Its Causes," Journal of Higher Education, Vol. 37 (11) (2016), p. 51-57, in Chinese.

[5] J. Y. Lou, et al, "A Research of Blended Teaching Based on the Flipped Classroom Model Applies to Vocational Education--Experiment in the Major of Numerical Control Lathe," Science Journal of Education, Vol. 4(2) (2016), p. 73-77.

[6] J. L. Shi and Y. H. Zhang, "Research on the Teaching Ability Development System of Young Teachers in Universities," Higher Agricultural Education, No. (6) (2013), p. 47-50, in Chinese.

[7] L. Q. Yang, "The Suggestions for Improving the Teaching Ability of Young Teachers in Universities," Education Exploration, No. (1) (2015), p. 128-130, in Chinese.

[8] J. Wang, "The training and Influence Factors on the Teaching Ability of Young Teachers in Universities," Journal of Liaoning Administration College, Vol 16(12) (2014), p. 107-108, in Chinese.

[9] Q. L. Zhu, “The Development of Professional for Foreign Language Teachers under the Inverted Classroom: Opportunities and Challenges," Education and Vocation, No. (30) (2015), p. 70-72, in Chinese. 